City University of New York (CUNY)

CUNY Academic Works

International Conference on Hydroinformatics

2014

Research And Application On The Coupled Method Of RemoteSensing And Ground-Monitoring Of Reservoir Storage Capacity

He Zhu

Hongli Zhao

Yunzhong Jiang

Li Wang

How does access to this work benefit you? Let us know!

More information about this work at: https://academicworks.cuny.edu/cc_conf_hic/316

Discover additional works at: https://academicworks.cuny.edu

This work is made publicly available by the City University of New York (CUNY).

Contact: AcademicWorks@cuny.edu 
$11^{\text {th }}$ International Conference on Hydroinformatics

HIC 2014, New York City, USA

\title{
RESEARCH AND APPLICATION ON THE COUPLED METHOD OF REMOTE-SENSING AND GROUND-MONITORING OF RESERVOIR STORAGE CAPACITY
}

\author{
HE ZHU (1), HONGLI ZHAO (1), YUNZHONG JIANG(1), LI, WANG(2) \\ (1):Department of Water resources, Institute of Water Resources and Hydropower Research, 1 \\ Yuyuantan South Road, Haidian District, Beijign, China
}

(2):Department of Water History, Institute of Water Resources and Hydropower Research, 1 Yuyuantan South Road, Haidian District, Beijign, China

\begin{abstract}
Reservoir storage monitoring is the basis of reservoir operation. The relationship curves of reservoir water level-area and water level-storage are the significant parameters of storage capacity calculation. With the long-term operation, both on the bottom and bank of the reservoir have erosion and deposition, causing the relationship of water level-area and level-storage changes, which leads to inaccuracy of reservoir storage capacity calculation with the original curves. It is costly to revise the curves of reservoir water level-area and water level-capacity by ground measurement termly. A coupled Method of Remote-sensing and Groundmonitoring of Reservoir Storage Capacity is proposed in this paper. Based on coupled data of satellite image of the reservoir water-area monitoring and the ground water-level monitoring on the same day, the relationship curves of reservoir water level-area and water level-capacity are updated, the calculation accuracy of reservoir storage capacity is improved. The Gangnan Reservoir is taken as an example for this research. $10 \mathrm{HJ}$-satellite images are used for revising the curve of reservoir water level-area and water level-capacity. The reservoir storage capacity differences between original and revised curves are analyzed and turned out to be reasonable.
\end{abstract}

\section{Introduction}

Water level-area curve and water level-capacity curve are essential characteristic curves for obtaining reservoir water storage, which plays a key role in reservoir operation. The traditional ways for getting the two curves are measuring contour-line area based on large-scale topographic maps made before the reservoir built [Zhou et al. 1986]. These methods suffer from poor topographic precision, moreover it is costly to revise the two curves by ground measurement termly, since the relationship of water level-area and level-storage changes with the long-term operation, both on the bottom and bank of the reservoir have erosion and deposition.

Remote sensing has the ability to obtain water body area in large extent rapidly and accurately. In this paper, we coupled the data of satellite image of the reservoir water-area monitoring and the ground water-level monitoring on the same day to correct water level-area curve and water level-capacity curve, then obtain the reservoir water storage based on the water level monitoring and the new water level-capacity curve more accurately. 


\section{Research areas and data}

\subsection{Overview of research area}

Gangnan reservoir is the most important water source on the Beijing-Shijiazhuang city section of the middle route of South-North Water Transfer Project (Fig. 1) which was selected as a research area in this study. It is on the middle-lower part of main stream of Hutuo Rive which is one of two tributaries in the Haihe River basin. It controls a drainage area of $15,900 \mathrm{~km}^{2}$ with a total run-off capacity of 1.571 billion $\mathrm{m}^{3}$ to achieve its main functions like flood control, water supply, irrigation and electricity generation. Gangnan reservoir has been running for over 50 years since it was built in 1958 and it has been supplying water to Beijing since the beginning of 2010 along with Huangbizhuang reservoir, Xidayang reservoir as well as Wangkuai reservoir. Figure 1 shows the water supply route of Beijing-Shijiazhuang section (Jing-Shi section) of the South-North Water Transfer Project and the location of the Gangnan reservoir and its water level gauge named Bashang which is located on the dam of Gangnan reservoir.

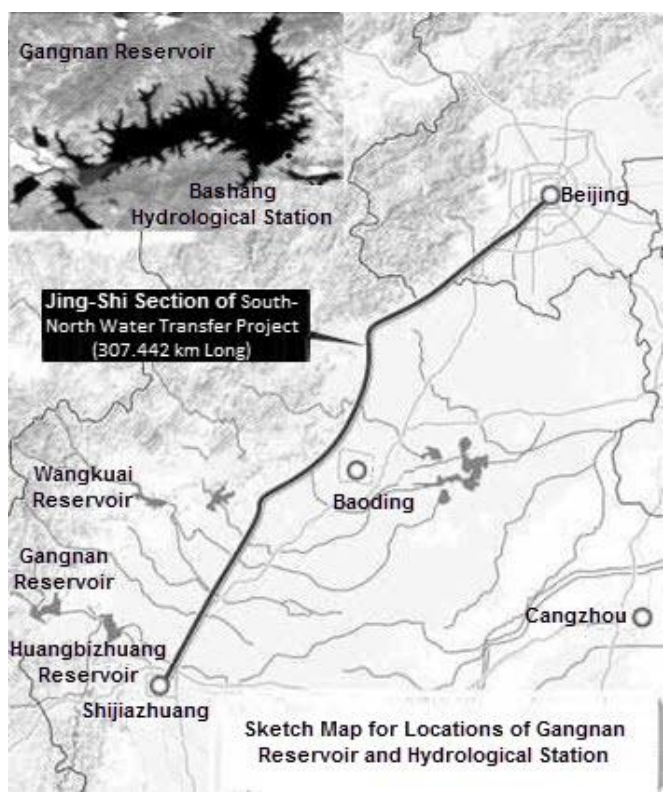

Figure 1. Sketch map for locations of Gangnan reservoir and its water level gauge

\section{2. data and pretreatment}

The data in this study includes multi-spectral remote sensing images, ground monitoring water level data and reservoir basic data such as the reservoir location information, underlying surface conditions, and the reservoir characteristic curves etc.

In term of remote sensing images, China Environment and Disaster Monitoring small satellite constellation $(\mathrm{HJ}-1 \mathrm{~A} / \mathrm{B})$ images were chosen as the main images source considering the integrated requirement of revisiting period and spatial resolution of monitoring. $\mathrm{HJ}-1 \mathrm{~A} / \mathrm{B}$ satellites have four 4 spectral bands and the images have the spatial resolution of $30 \mathrm{~m}$, the breadth of one scene reaches $360 \mathrm{~km}$. They have imagery of the whole globe every two days with $\mathrm{A} / \mathrm{B}$ double operational satellites.

This study uses 10 phases of HJ-1A/B images over Gangnan reservoir region on 2010-0423, 2010-05-24, 2010-06-05, 2010-07-06, 2010-07-08, 2010-07-20, 2010-08-16, 2010-08-22, 2010-09-11 and 2010-09-13 to monitor and analyze reservoir storage state. These images are 
pretreated with radiometric calibration, atmospheric correction, cropping etc., then the ENVI EX object-oriented module is used to extract water body area.

In terms of ground monitoring data, the daily water level of Gannan reservoir on the same day with the satellites images captured were collected, the water body area and storage of the reservoir were calculated by original water level-area curve and water level-capacity curve of the reservoir .

\section{A Variation analysis of reservoir characteristic curves}

The water areas extracted from satellite images were compared with the values looked up from the original water level-area curve used the water level monitored at bashing gauge on the same days. The difference was showed in Fig. 2 and table 1.

Table 1. Comparison between water areas extracted by RS (remote sensing) and water areas on original water level-area curve

\begin{tabular}{|c|c|c|c|}
\hline Date & $\begin{array}{c}\text { Water } \\
\text { levels(m) }\end{array}$ & $\begin{array}{c}\text { Water areas extracted } \\
\text { by RS }\left(\mathrm{km}^{2}\right)\end{array}$ & $\begin{array}{c}\text { Water areas on original } \\
\text { water level } \\
\text {-area curve }\left(\mathrm{km}^{2}\right)\end{array}$ \\
\hline $2010 / 8 / 16$ & 186.98 & 27.10 & 29.53 \\
\hline $2010 / 8 / 22$ & 187.57 & 29.17 & 30.40 \\
\hline $2010 / 7 / 8$ & 187.76 & 29.14 & 30.68 \\
\hline $2010 / 7 / 6$ & 187.81 & 28.71 & 30.75 \\
\hline $2010 / 7 / 20$ & 187.82 & 28.72 & 30.76 \\
\hline $2010 / 6 / 5$ & 188.91 & 30.78 & 32.35 \\
\hline $2010 / 9 / 11$ & 190.07 & 31.54 & 34.94 \\
\hline $2010 / 9 / 13$ & 190.27 & 33.08 & 35.40 \\
\hline $2010 / 5 / 24$ & 191.81 & 36.31 & 38.80 \\
\hline $2010 / 4 / 23$ & 193.84 & 41.50 & 42.76 \\
\hline
\end{tabular}

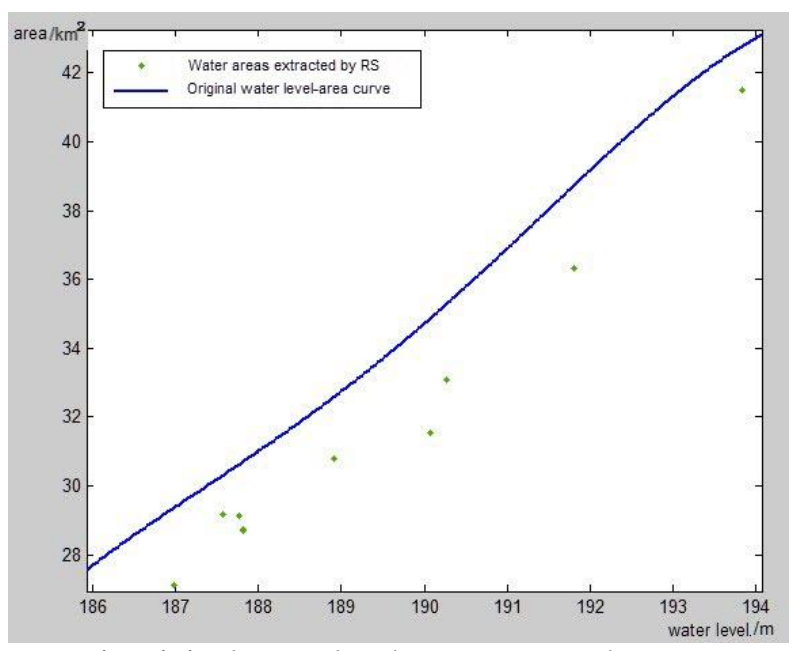

Figure 2. Gangnan reservoir original water level-area curve and water areas extracted by RS 
As showed in table 1 and Fig.2, at the same water level, the values of water body area got from remote sensing images are generally smaller than the values got from the original water levelarea curve.

To avoid the potential system error resulted from single image sources, the other two satellite image sources Landsat TM images (multispectral spatial resolution of $30 \mathrm{~m}$, width of $185 \mathrm{~km}$ ) and ZY-3 satellite images (spatial resolution of $6 \mathrm{~m}$, width of $51 \mathrm{~km}$ ) were selected to verify the water body areas extracted from $\mathrm{HJ}-1 \mathrm{~A} / \mathrm{B}$ images.

The results from Landsat TM images and HJ-1A/B images on 2010-8-22 are close to each other and the both results are less than the value got from the water level-area curve, as in the case among the results from the ZY-3 images, HJ-1A/B images and water level-area curve on 2012-9-16.

Table 2. Comparison among water area based on three kinds of data source

\begin{tabular}{|c|c|c|c|c|}
\hline Data & $\begin{array}{c}\text { Water } \\
\text { level }(\mathrm{m})\end{array}$ & $\begin{array}{c}\text { Water area by TM } \\
\text { data }\left(\mathrm{km}^{2}\right)\end{array}$ & $\begin{array}{c}\text { Water areas by HJ } \\
\text { satellites data }\left(\mathrm{km}^{2}\right)\end{array}$ & $\begin{array}{c}\text { Water area on water } \\
\text { level-area curve }\left(\mathrm{km}^{2}\right)\end{array}$ \\
\hline $2010 / 8 / 22$ & 187.57 & 29.26 & 29.17 & 30.40 \\
\hline Absolute difference based on Landsat TM & 0.09 & 1.14 \\
\hline Data & $\begin{array}{c}\text { Water } \\
\text { level }(\mathrm{m})\end{array}$ & $\begin{array}{c}\text { Water area by } \\
\text { ZY-3 data }\left(\mathrm{km}^{2}\right)\end{array}$ & $\begin{array}{c}\text { Water areas by HJ } \\
\text { satellites data }\left(\mathrm{km}^{2}\right)\end{array}$ & $\begin{array}{c}\text { Water area on water } \\
\text { level-area curve }\left(\mathrm{km}^{2}\right)\end{array}$ \\
\hline $2012 / 9 / 16$ & 191.93 & 42.32 & 42.21 & 43.68 \\
\hline \multicolumn{2}{|c|}{ Absolute difference based on ZY-3 } & 0.11 & 1.36 \\
\hline
\end{tabular}

It is concluded that the water areas got from the HJ-1A/B images are credible based on above comparisons. The satellites images recorded the real water areas of the reservoir at those points in time.

The differences between the area extracted from remote sensing images and from the original reservoir characteristic curves demonstrate that the actual reservoir characteristic curves are not constant. The reservoir water body areas at the given water levels indicate a trend of decrease over many years. A possible reason is that the shapes of reservoir banks and bottom have changed due to erosion and deposition after long time operation. Therefore, in order to monitor the reservoir water storage more accurately, the reservoir characteristic curves are required to be revised. To do this work, the satellite images are economical and timely information sources about water body area, also easy to get.

\section{The coupled Method of Remote-sensing and Ground-monitoring of Reservoir Storage Capacity}

Based on above analysis of issues about monitoring reservoir water storage, this study establishes a coupled method of the ground monitoring water level data and remote sensing reservoir water body area to revise the reservoir characteristic curves and enhance the accuracy of water storage monitoring.

\subsection{The method outline}

The general idea is to couple the remote sensing reservoir water body area and the ground monitoring water level on the given days, then the original reservoir water level-area curve can be revised with the coupled data, the original reservoir water level-storage curve can be revised 
with the revised water level-area curve. The water storage got from the ground monitoring water level and the revised water level-storage curve will be more accurate for taking into account of water area variation at given water level over long time reservoir operation. The method outline is as follows in Fig.3.

In the actual application conditions, reservoir characteristic curves would be revised at regular intervals, which will achieve continuously improving the accuracy of monitoring reservoir water storage.

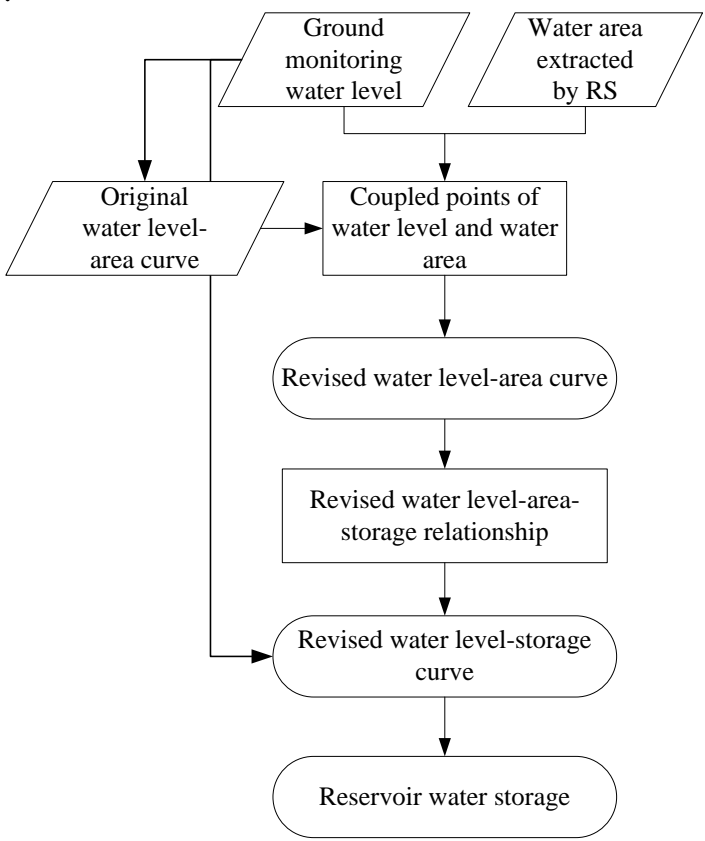

Figure 3. The outline of the coupled method of remote sensing and ground motoring

\subsection{Revise of reservoir water level-area curve}

A polynomial fitting model derived from the Taylor expansion function was utilized to do water level-area curve fitting based on the coupled data (the remote sensing reservoir water body area and the ground monitoring water level on the given days) and the original reservoir water levelarea curve.

The selected $\mathrm{n}$-degree polynomial function of water area $\mathrm{A}$ about variables water level $\mathrm{H}$ is shown as follows:

$$
A(H)=\sum_{n=1}^{\infty} \frac{1}{(n-1) !} \frac{d^{n-1} A\left(H_{i}\right)}{d H^{n-1}}\left(H-H_{i}\right)^{n-1}
$$

Ignoring infinitesimal of the variable-water level $H$, equation (1) is written as the following polynomial expansion formula ( Tian et al. 2007; Ding 2011):

$$
A(H)=\sum_{n=0}^{\infty} a_{n} H^{n}
$$

According to sample of points $(\mathrm{H}, \mathrm{A})$, the optimal approximation of coefficients of the expansion formula can be obtained by the least squares method. The sample points include the coupled data of the remote sensing reservoir water body area and the ground monitoring water 
level on the given days, and the points extracted from the original water level-area curve with regular interval $\Delta \mathrm{H}$.

The coefficients of the expansion formula are put into to the continuous function of variable water level. For obtaining the degree of polynomial, we iterate the trials about the correlation coefficient of the function of sample points maximum using the sequence of degrees counting from integer 1 to $\boldsymbol{n}(n=1,23, \ldots)$ until the correlation coefficient $R$ (Song et al. 2011) between the function and the sample points is maximum, which makes the polynomial function become the demand function.

\subsection{Revise of water level-storage curve}

If the segment water volume between two adjacent water level is treated as frustum volume, the water frustum volume between two adjacent water level can be expressed as follows (Tan and Shen 2009; Li 2010):

$V_{i}=\frac{H_{i+1}-H_{i}}{3}\left(A_{i}+A_{i+1}+\sqrt{A_{i} A_{i+1}}\right)$

where $V_{i}$ is water volume between two adjacent water level; $H_{i}$ is the lower water level of segment No. ${ }^{i}$; $A_{i}$ is the water area corresponding to water level $H_{i}$ and looked up from the revised reservoir water level-area curve with $H_{i}$. Water volume below dead water level can be calculated as the volume of an inverted cone.

So the total water storage $\mathrm{V}$ below the given water level $\mathrm{H}_{\mathrm{n}}$ is:

$V=\sum_{i=1}^{n} V_{i}$

The revised curve of $\mathrm{H} \sim \mathrm{V}$ can be created using the eq.(4) and eq.(5).

\section{The method application on Gangnan reservoir}

\subsection{Revise of Gangnan reservoir characteristic curves}

The 10 coupled data of ground monitoring water level and remote sensing water area were used to revise the Gangnan reservoir characteristic curves. The polynomial's degree and coefficients were optimizated using Matlab software. The fourth degree polynomial is obtained as followed:

$$
A(H)=a_{0}+a_{1} H^{1}+a_{2} H^{2}+a_{3} H^{3}+a_{4} H^{4}
$$

where $\boldsymbol{A}(\boldsymbol{H})$ is the revised function of water level-area; $\boldsymbol{I}$ is the corresponding water level; $a_{0}, a_{1}, a_{2}, a_{3}$ and $a_{4}$ are coefficients. $a_{0}=5.837 \times 10^{-6}, a_{1}=-0.005686$, $a_{2}=1.982, a_{3}=-295.5, a_{4}=1.603 \times 10^{4}$. The correlation coefficient $R$ (Song et al. 2011) between the function and the sample points equals 0.9998 .

The revised reservoir water level-area curve and water level-storage curve are presented in the following figures4 5:

As showed in the figures4 5, revised Gangnan reservoir characteristic curves are lower than the original curves. It means that the water area and water storage at the given water level are smaller than the original values. As analysed above, a possible reason is that the shapes of reservoir banks and bottom have changed due to erosion and deposition after long time operation. 


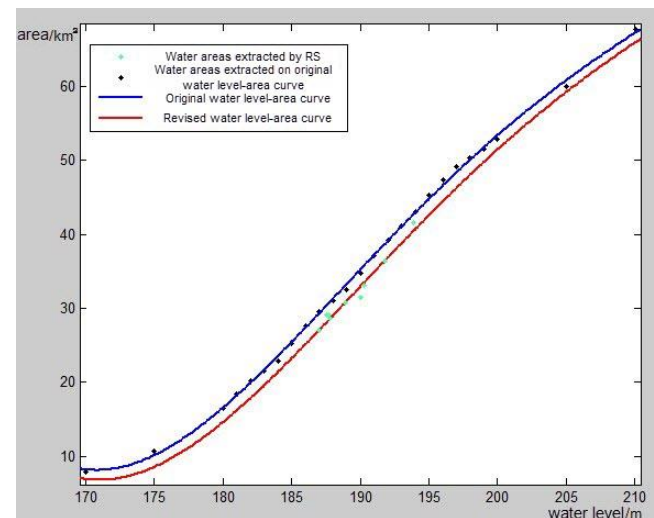

Fig 4. Revised water level-area curve

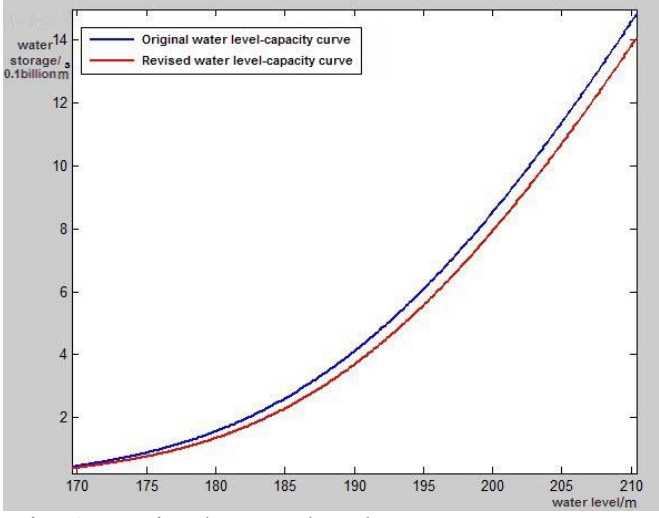

Fig 5. Revised water level-storage curve

\subsection{The improvement verification of water storage monitoring}

In order to verify the rationality and accuracy improvement of the revised reservoir characteristic curves, the restoration calculation of water storage in 2011 was performed. Gangnan reservoir's monthly water storage changes were calculated using the ground monitoring inflow and outflow. The other two water storage changes in the corresponding period were looked up from original water level-storage curve and from the revised water levelcapacity curve respectively with the ground monitoring water level. The differences of the three water storage changes are shown below:

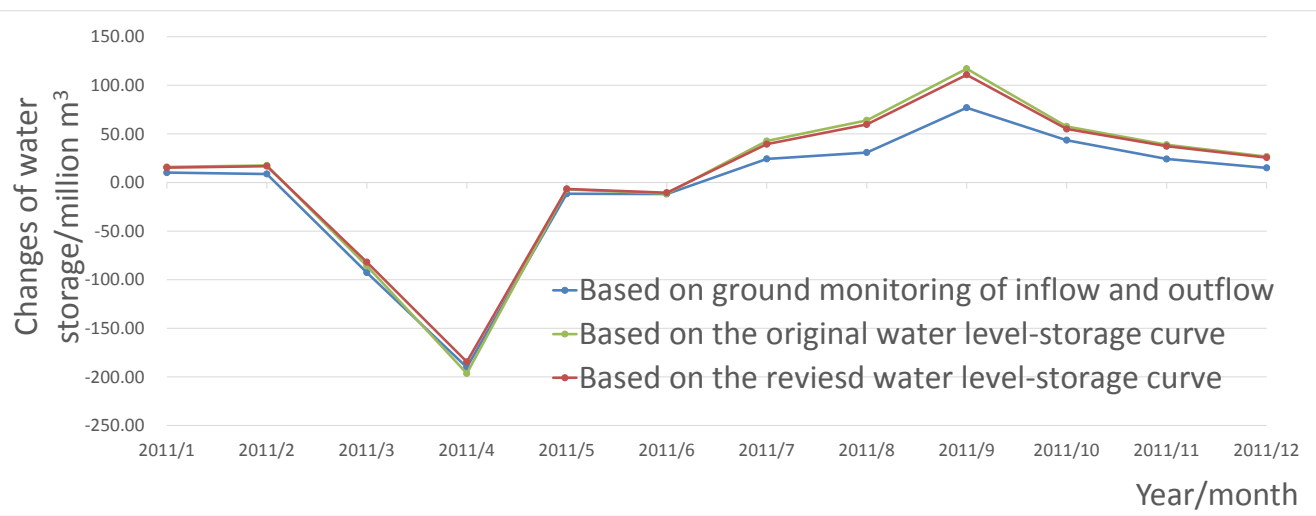

Figure 6. Test of accuracy of results based on the restoration calculation of water storage

Figure 6 shows that water storage changes from the revised water level-capacity curve are slightly closer to changes calculated by the restoration calculation of water storage. This demonstrates the better accuracy of monitoring Gangnan reservoir water storage by the coupled method of remote sensing data and ground monitoring data.

Limited to quantity of 10 remote sensing data joined into the application, the accuracy improvement is not significant. However, constantly revising reservoir characteristic curves with remote sensing data will continuously improve the accuracy within a certain range.

\section{Conclusions and discussion}

The precision of monitoring reservoir water area and water storage is hard to be improved due to the difficulty to update reservoir characteristic curves by traditional ground measurement methods. Remote sensing technology provides the advantages for obtaining area monitoring 
data fast and accurately. In this paper, multi-temporal remote sensing images were chosen to extract reservoir water area and then coupled with ground monitoring water level on the given days to revise the reservoir characteristic curves. The improved accuracy of water storage monitoring was obtained with revised curves and ground monitoring water level.

The observation about water area from remote sensing images indicates that the water areas at the given water levels are generally smaller the values described in the original reservoir water level-area curve. Due to reservoir sedimentation for many years, it is considered to be reasonable that water capacity will shrink after long time reservoir operation. It is the reason that the reservoir characteristic curves have to be revised at fixed periods.

For a reservoir in service, the coupled method of remote-sensing and ground-monitoring of reservoir storage proposed in this paper could be used to revise water level-area and water level-storage curves except the part below the dead water level.

\section{Acknowledgments}

This research was supported by the project of "Study on Information Acquisition Technology for River Basin Based on Internet of Things" [Grant No.2013BAB05B01] and the project of "High resolution earth observing system-water application demonstration" [Grant No. 08Y30B07-9001-13/15-01]

\section{REFERENCES}

[1] Ding, Z.X. 2011. "Study on method for measurement of reservoir water-level and water surface curve based on DEM combined with remote sensing." Water Resources and Hydropower Engineering 41(1):83 86.

[2] Li, H., Li, C.A., Zhang, L.H. and Tian, L.Q. 2008. "Relationship between water level and water area in Poyang Lake based on Modis image.” Quaternary Science 28(2):332 337.

[3] Li, J. 2010. "Water capacity curve measurement based on GPSRTK technology.” Pearl River (3):9,24.

[4] Lu, J.J. and He, C.L. 2003. "Re-measurement of storage-capacity curve of Fengman Reservoirby satellite remote sensing technique." Hydro-Science and Engineering (4):60 63.

[5] Qi, S.H., Jun Gong, Shu, X.B. and Chen, L.F. 2010. "Study on inundation extent water depth and storage capacity of Poyang Lake by RS.” Yangtze River 41(9):35 38.

[6] Song, Q.M., Xiong, L.H., Xiao, Y., Chen, X. and Liu, L.G. 2011. "Study on Relationship between Lake Area and Water Level of Dongting Lake Based on MODIS Images." Water Saving Irrigation (6):20 26.

[7] Tan, D.B. and Sheng, S.H. 2009. "Reservoir Capacity Calculation and Accuracy Analysis Based on Grid DEM.” Journal of Yangtze River Scientific Research Institute 26(3):49 52,56.

[8] Tian, Y., Lin, Z.J., Lu, X.S. and Liang, Y. 2007. "Reservoir Water level water surface curve measurement based on RS." South to North Transfers and Water Resources \& Technology 5(1):58 60.

[9] Zhou, Z.H., Sheng, Z.Y., Shi, X.C. and Li, T.X. 1986. Planning of Water Conservancy and Hydropower]. China: China WaterPower Press. 